\title{
Forecast Jointed Rock Mass Compressive Strength Using a Numerical Model
}

\author{
Anatoliy Protosenya ${ }^{1}$, and Pavel Verbilo ${ }^{1, *}$ \\ ${ }^{1}$ National Mineral Resources University, 199106 St Petersburg, Russia
}

\begin{abstract}
The method of forecasting the strength of the jointed rock mass by numerical modeling of finite element method in ABAQUS was described. The paper presents advantages of this method to solve the problem of determining the mechanical characteristics of jointed rock mass and the basic steps of creating a numerical geomechanical model of jointed rock mass and numerical experiment. Numerical simulation was carried out with jointed rock mass in order to obtain the ratio of strain and stress while loading the numerical model, determining parameters of quantitative assessment of the impact of the discontinuities orientation on the value of the compressive strength, compressive strength anisotropy. The results of the numerical experiment are compared with the data of experimental studies investigations. Innovative materials and structures are analyzed in this paper. The results that were obtained by calculation show qualitative agreement with the results of laboratory experiments of jointed rock mass.
\end{abstract}

\section{Introduction}

The rock mass is a system of discrete blocks of intact rock that are separated by fractures, structural weakening zones, different defects that have a significant influence on mechanical characteristics of the jointed rock mass [1]. Methods of determining mechanical characteristics of the rock mass are divided into direct and indirect. Direct methods are used in the laboratory or field conditions, where the rock mass is loaded with the help of press installations and then the value of strength in uniaxial compression is determined. Laboratory or field experiments for testing of the rock mass is the most reliable way to determine the mechanical characteristics, but in a laboratory conducting tests on samples of large dimensions are associated with difficulties and high cost [2-3]. Other approaches to determine the strength and deformation characteristics of the rock mass are indirect methods, which include: empirical, analytical and numerical methods. The empirical approach [4-6] for determining the mechanical characteristics of the rock mass is based on case history, which is widely used in the design of tunnels by using the classification systems of the rock mass. The main disadvantage of this method is the lack of a mathematical framework for the establishment of geomechanical model. At present in the domestic industry in order to determine the strength and deformation properties of jointed rock mass empirical coefficient of structural weakening is used that takes into account only

* Corresponding author: pashaverbilo@,mail.ru 
one characteristic of jointed rock mass, the distance between discontinuities. In most cases this method is not scientifically justified and therefore can leads to inaccurate results. Analytical methods 11 are very convenient to use in geomechanics, but their application to determine the mechanical properties of the rock mass does not allow to get solution for system, which including a complex system of discontinuities and intact rock.

A big impulse for the development of numerical approaches to determine the strength and deformation properties of jointed rock mass was the development of computer technology. Development of numerical methods and their integration with existing analytical methods for solving problems, which are related with the determination of influence on the value of the rock mass mechanical properties, the scale effect, is the subject of serious research, because there are uncertainties, which are associated with the transition from the test results of intact rock to the physical and mechanical properties of the rock mass. The main advantage of numerical methods is the ability to create a geomechanical model of the rock mass on the basis of accounting of discontinuities system and interaction conditions of intact rock along of discontinuity 12 .

The finite element method is one of the most widely used numerical methods for determining the mechanical characteristics of jointed rock mass, as it allows explicitly take into account fractures of rock mass and conditions of interaction of rock blocks 13 . Recently a lot of researches are conducted using the finite element method under jointed rock mass to describe its mechanical behavior 14 .

\section{Materials and Methods}

Construction of numerical model of scale-inhomogeneous rock mass requires singling out and analysis of typical structures of discontinuities by geotechnical data, because the structure of discontinuities reflect the structural features of the rock mass and determine form of blocks of intact rock. The size of the rock block, inside which the conditions quasicontinuous and quasihomogeneity are satisfied, is representative elementary volume. Results of laboratory experiments on the compression press equipment well describe the mechanical behavior of the elementary intact rock block. The behavior of the rock within the representative elementary volume in the numerical model is described by results of laboratory experiments. Results of laboratory experiments is achieved by compilation of a model of intact rock and consistent quality correction to match the results obtained in laboratory tests with the possibility of quantitative differences within the margin of error. The mechanical behavior of intact rock in the numerical model will correspond to reality, if we get results that are similar to the experimental results.

We must always remember that in the rock mass there are several levels of typical structures of discontinuities and defects. Each sample of every structure consists of a finite number of previous level structures, which leads to the requirement of compliance of conditions of quasihomogeneity and quasicontinuous which are calculated on each level. This requirement is set by the need to eliminate the influence of the scale effect on the final result.

The subsequent development of geomechanical numerical model requires a similar sequential execution of numerical experiments by modeling of interaction of blocks of intact rock along the contact between them in order to achieve result that is not quantitatively different from the laboratory experiment on direct shear. This step is the most important, because carried out research with rock mass indicates that discontinuities, as the main factor, mostly affect the quantitative value of mechanical characteristics of the rock mass. Based on the above steps we construct a common geomechanical model of the rock mass, taking into account the features of the behavior of blocks of intact rock and their interaction on the contact during loading. 
Changing the size of the numerical models of rock mass allows reasonable calculation if scale effect. The model can be applied for numerical experiments with different systems of discontinuities.

\section{Formulation of the problem and description of the study}

Aspects of modeling of rock mass sample impaired by discontinuities system during uniaxial and biaxial compression testing using the finite element method in ABAQUS to study the anisotropy of uniaxial compression strength of jointed rock mass are considered in this paper, the procedure of simulation is described consistently. Graphs of the stressstrain dependence and graphs of the dependence of the compressive strength on the angle of discontinuities in the rock mass built on the results of the calculations. We use numerical geomechanical model of the rock mass to study the behavior of the rock mass under the influence of loads and for determination of mechanical characteristics of jointed rock mass. This model reflects actual mechanical characteristics of the rock mass and laws of its changes in the space by interconnected mathematical and formal logic expressions. The task is to build a numerical model of jointed rock mass and model's test under uniaxial and biaxial compression in order to obtain the limit values of strength and to obtain an influence estimation of discontinuities parameters in conjunction with an applied lateral load on the value of compression strength.

It is assumed that the destruction in the numerical experiment of a sample of the rock mass will occur on the surfaces of the weakening. Destruction of blocks of intact rock in the model is not provided. In the numerical model interaction on the contact between the blocks is defined by friction, as it is assumed that the cohesion between blocks of intact rock is no taken into consideration.

Actually, cohesive bonds in jointed rock mass along the contact interaction of blocks of intact rock have small values, so we can ignore cohesion in modeling of jointed rock mass 17. Representative elementary volume of intact rock in the study under consideration is form of parallelepiped. Therefore, system of the rock mass discontinuities is a system of vertical and horizontal parallel lines with a constant distance between them.

Basic information about mechanical characteristics of the intact rock and the discontinuities that was used in the modeling is given in 0 .

Table 1. The mechanical properties of the intact rock and discontinuity.

\begin{tabular}{llll}
\hline Intact rock & Density, $\left(\mathrm{kg} / \mathrm{m}^{3}\right)$ & Young's modulus, E (GPa) & Poisson's ratio \\
\hline & 2700 & 2 & 0,3 \\
\hline Discontinuity & Joint friction angle, $\left(^{\circ}\right)$ & Joint cohesion, [MPa] & \\
\hline & 21 & 0 & \\
\hline
\end{tabular}

The most time-consuming step in the construction of numerical geomechanical model of the rock mass is the geometric construction of the rock mass, as it is formed by a plurality of independent units that must be simulate.

To solve this problem two options scheme application loads on the numerical model of the rock mass have been chosen. In the numerical model vertical load in combination with various lateral loads $(0,10,20,30 \mathrm{MPa})$ were set. Lateral load were applied to the side surface uniformly over the whole area. Typical design schemes of load application to the numerical model during the numerical experiment are shown in 0 , wherein 0 a shows a scheme of uniaxial compression. 0b shows biaxial compression test.

Vertical load to the numerical model of the rock mass was provided through a specified move to absolutely rigid plate located on the top surface of the rock mass. Lower plate in 
the numerical experiment was also absolutely rigid. Any possible move prohibits to support plate. Thus, in the blocks of intact rock and contract between them is occurring the emergence and subsequent redistribution of stresses during the motion of the plate on the ordinate. The loss of the bearing capacity of the model occurs after reaching the limit state of numerical model of jointed rock mass.

Models of jointed rock mass with angles to the horizontal plane of the discontinuities of $0,30,45,60,90$ degrees were built for research strength anisotropy of uniaxial and biaxial compression of jointed rock mass. For each models carried out of simulation tests in uniaxial and biaxial compression. Several simulation sets had been described above. Black lines within the test sample of the jointed rock mass in 0 indicate the discontinuity, and the intersection of the lines with each other forms blocks of simulated intact rock.

The results are analyzed after carried out virtual experiments. Results of virtual experiment are summarized in the graphs of the relative value of the stress to the relative magnitude of strains of jointed rock mass where the angle of discontinuities is 45 degrees (0). Also below is a graph of relative magnitude of the strength on uniaxial and biaxial compression on the angle of inclination of discontinuity to the horizontal plane (0).

As you can see, the orientation of discontinuities in the rock mass has a significant impact on its strength and deformation characteristics and the process of deformation and failure of the rock mass in volume state of stress occurs in the form of shear and breakout, which is confirmed by experimental studies [18-19].

The greatest value of the uniaxial compression strength belongs to the model of the rock mass with an angle of discontinuities 0 degrees to a horizontal plane (0). Further, there is gradual decline in the value of the compression strength of the jointed rock mass by increasing the angle of discontinuities to a horizontal plane, this dependence can be described by a linear relationship. The biggest difference from the compression strength of intact rock and compression strength of a rock mass belongs to rock mass with the angle of discontinuities to a horizontal plane 55 degrees. This ratio is typical for this system of discontinuities. The subsequent increasing of the angle of inclination of discontinuities to the horizontal plane is accompanied by a gradual increasing in the value of the strength of the rock mass under uniaxial and biaxial compression.

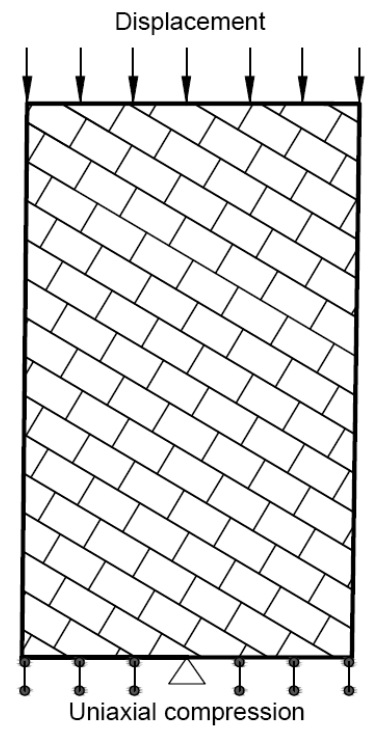

a

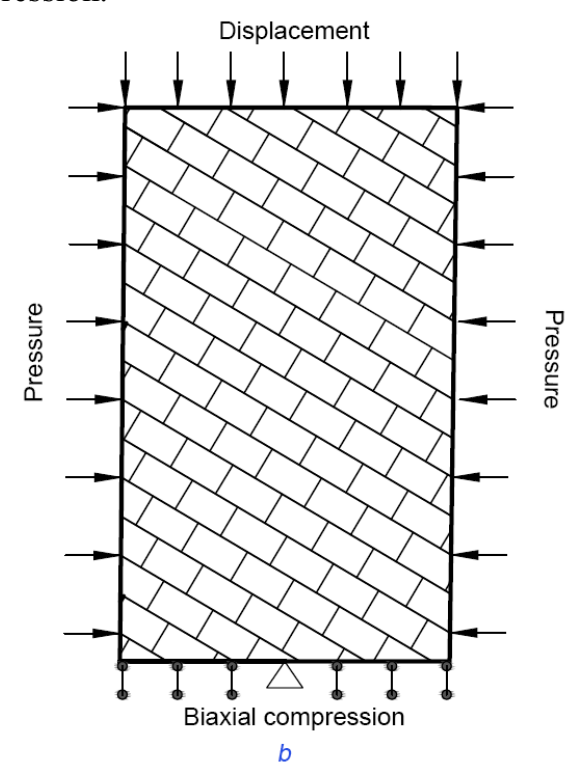

b

Fig. 1. Schemes of loads to models in the numerical experiment: (a) scheme of uniaxial compression; (b) scheme of biaxial compression. 
The simulation results ( 0 ) show that the increase in load leads to compaction of jointed rock mass and rigidity increased. With further load increasing blocks are displaced relative to each other and form voids within the array. When the shear occurs it leads to separation of intact rock along the discontinuity 17 . But shear occurs when the shear stresses on the micro areas reach a critical value. Similar shears take place all over the jointed rock mass, which leads to increase of the size of model, that is to say dilatancy effect is observed. It should be noted that rock mass, without applied lateral load, has the lower value of compressive strength. Rock mass has brittle deformation, this fact is confirmed by realized numerical experiments.

In 0 the mechanism of rock mass deformation is considered under biaxial compression. Diagrams of stresses distribution in the rock mass during deformation are shown in 0 . Micro shears occur during the initial deformation that leads to the formation of micro discontinuities of separation. Hardening occurs in the next step of deformation, which leads to an increase of stresses in the rock mass. The contact area of interaction between the intact rock blocks (the area that takes the load) is reduced with the hardening of the rock mass. Further, the shear deformation is accompany by the formation of voids and increase of volume of the model. These two processes determine the value of the jointed rock mass compressive strength [18-19].

Thus, at the beginning of the loading deformation of the rock mass has is linear character. After reaching the elastic limit of irreversible deformation occurs that extends to the maximum of compression strength. At this stage in the rock mass shears are taken place along of contacts between blocks of intact rock. It results in formation of main shear surface in the model. This section of the diagram which continues to the maximum magnitude of compressive strength is characterized by homogeneous deformations over the whole volume of the jointed rock mass. On the maximum of compressive strength deformation of this character stops. After passing through the maximum deformation occurs on area of residual deformations, which continues until the limit of residual strength. The result is the destruction of the rock mass along the main sliding surface, where maximum shear stresses have been formed. The above-described behavior of jointed rock mass during deformation experimentally was determined in laboratory conditions on press equipment [18-19].

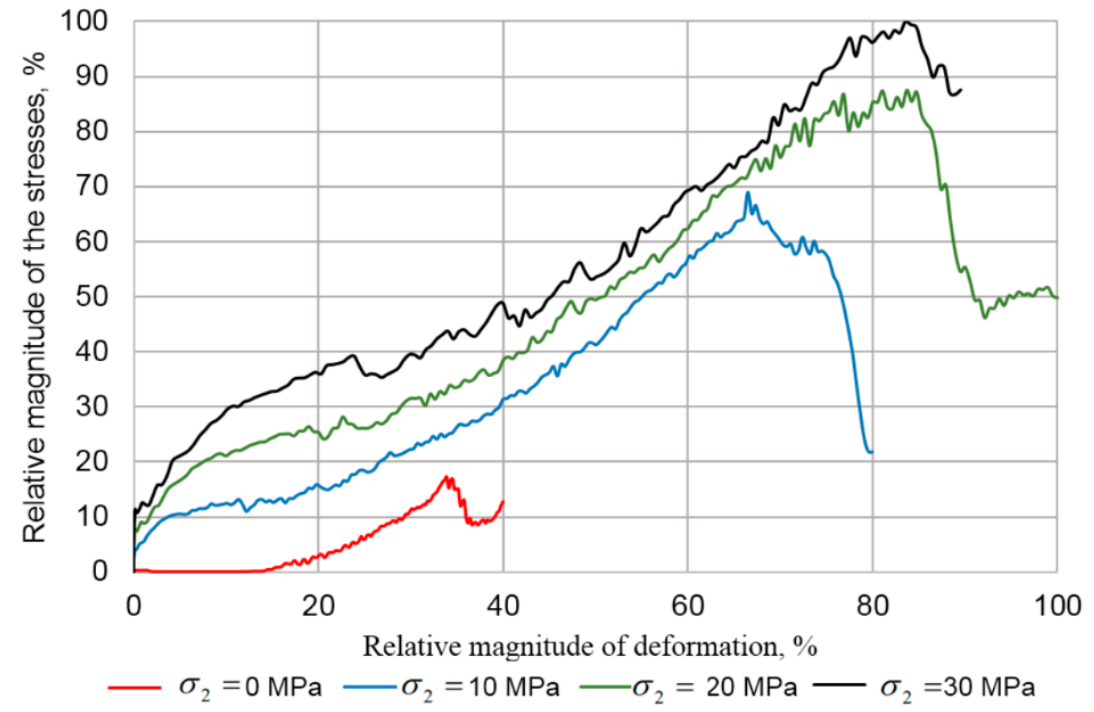

Fig. 2. Graphs of dependences of the relative magnitude of the stresses on the relative magnitude of deformation of the rock mass with an angle of discontinuities to the horizontal plane 45 degrees. 


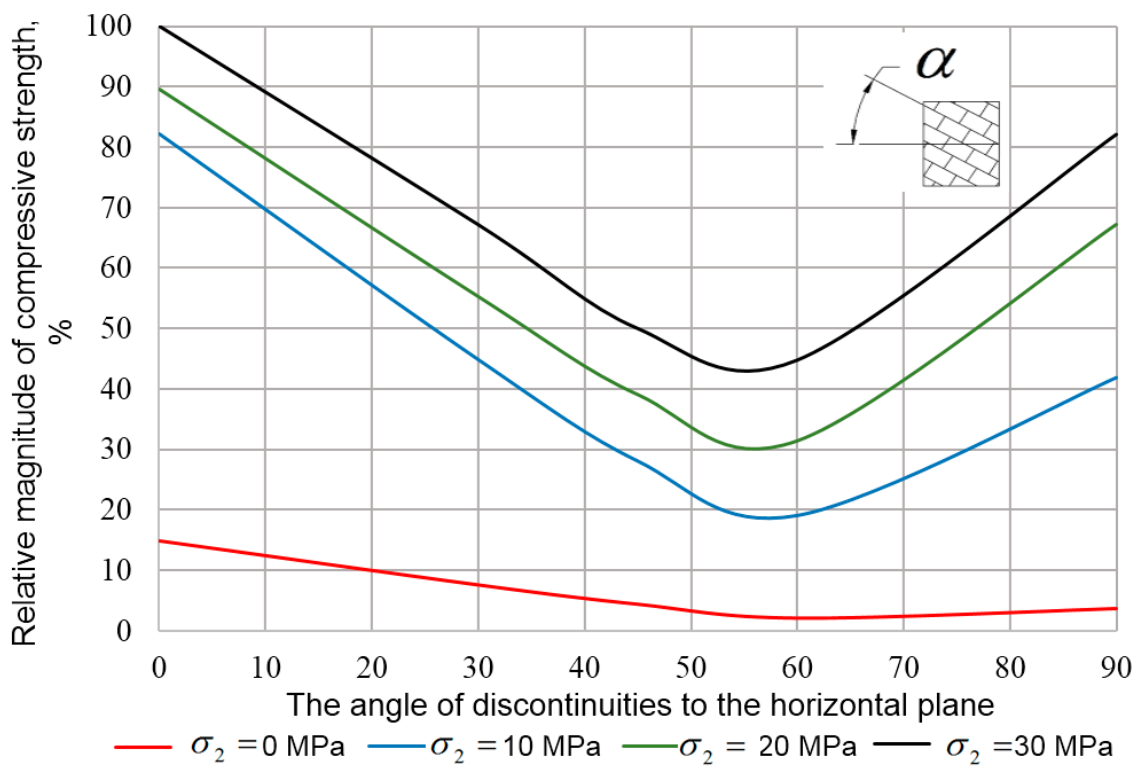

Fig. 3. Graphs of dependences of the relative magnitude of compressive strength on the angle of discontinuities to the horizontal plane at different lateral loads.

Increased strength with increasing lateral pressure is explained based on the assumption that the jointed rock mass has an internal friction which increases with increasing pressure. By analyzing the results of the numerical experiment we can make the following conclusions: jointed rock mass had destroyed by slide. The magnitude of the failure stress, the magnitude of the residual strain and the angle of orientation of the slide plane depend on state of stress and angle of discontinuities in the rock mass to the horizontal plane; the increase of lateral stress leads to increased shear strength at the contact between the intact rock blocks. Discontinuities are the cause of discontinuities of separation during deformation of the jointed rock mass. Concentration of stresses on the surfaces of defects leads to emergence of discontinuities of separations.

\section{Comparison of analysis results}

The article describes a numerical method for determining the strength and deformation characteristics of fractured rock mass using the finite element method. Numerical experiments were done with jointed rock mass of constant size by varying lateral loads and angle of discontinuities to horizontal plane. As a results dependence of strength on biaxial and uniaxial compression on the direction of force application to the sample of jointed rock mass was derived. The results were compared with similar studies with jointed rock mass, which were done by other researches $20-22$, where numerical simulation was carried out on basis of experimental data obtained by testing samples of the jointed rock mass in the laboratory. The results obtained in this study have a good match convergence with experimental results 17 . The experimental results show that the structural defects have such as discontinuities in the rock mass has a significant impact on the value of the strength and deformation characteristics of the jointed rock mass and strength, and deformation characteristics depend on the direction of the load in relation to major system of discontinuities [20-26]. 


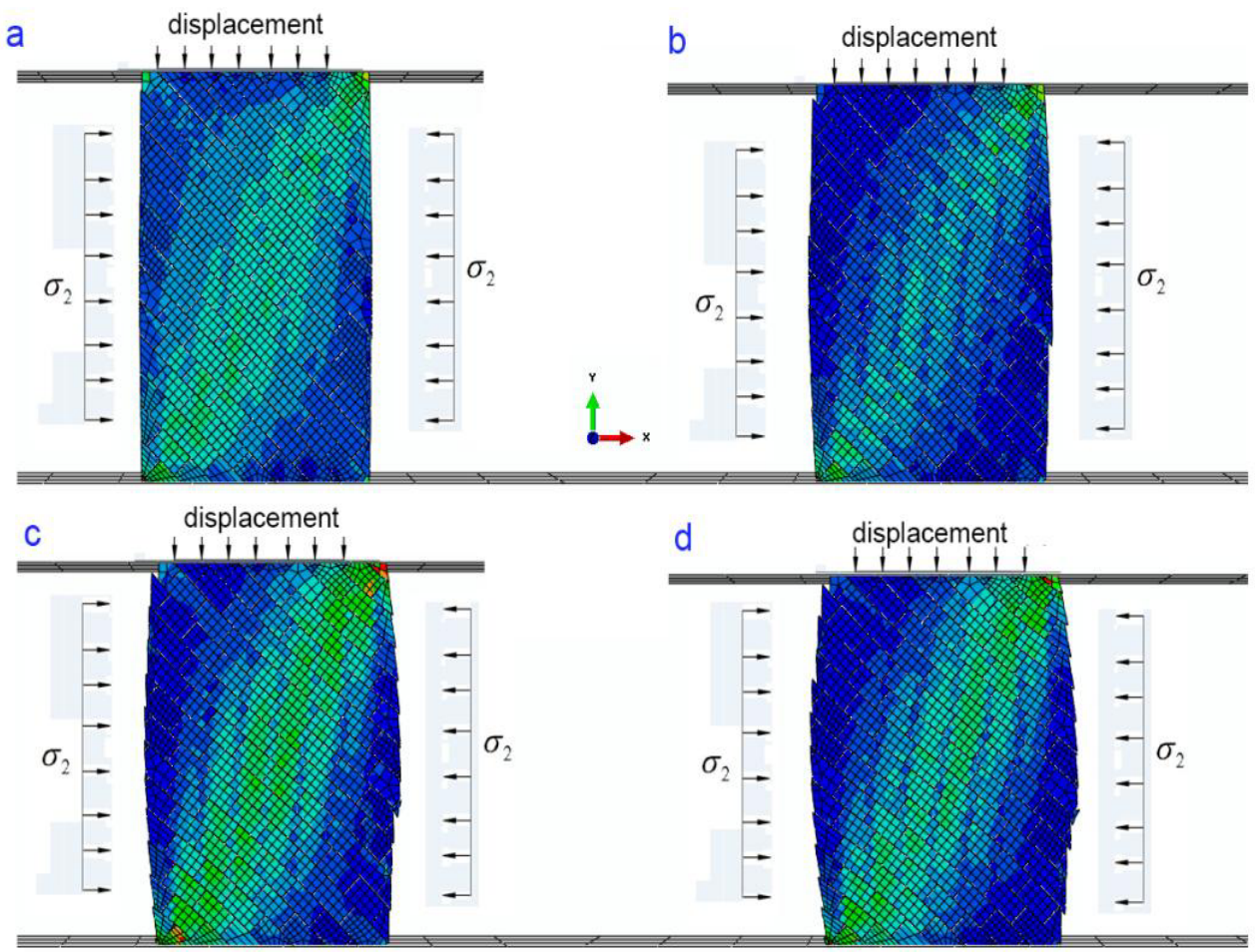

Fig. 4. The diagram of the stresses distribution in the numerical model during deformation: (a) first stage; (b) second stage; (c) third stage; (d) forth stage.

\section{Conclusions}

The most difficult tasks for geomechanics are related with the definition of mechanical characteristics of jointed rock mass. Application of numerical methods allows to solve such problems. The main goal when we using numerical modeling application is to define of accuracy of results. Comparison with results of experiment allows to determining the accuracy of the numerical model and its adequacy to real conditions. Though the possibilities of numerical modeling methods are very high and they allow to process and solve large number of complex systems of equations.

Quantitative accuracy of the results is still an important issue and requires further research. Thus, application of numerical methods allows to solve complex problems by linking scientific achievements in geomechanics with actively developing computer technologies. If in the laboratory conditions large size sample of jointed rock mass can not be studied, the use of numerical methods, in this case, the finite element method, allows to take into account the discontinuities and obtain different mechanical parameters which depend on the direction of the load in relation to the basic system of discontinuities of the jointed rock mass.

Also numerical experiments with models of jointed rock mass of different sizes allow to determine the reasonable limits of homogeneous rock mass size and scale effect. Anisotropy of strength is characteristic for jointed rock mass, this fact is explained by the presence of defects in the form of discontinuities in the rock mass. Quantifying such effect of anisotropy is possible to obtain with the help of the finite element method. It is required to perform because it is a very important stage in the design of underground structures. 
Further researches on the development of numerical geomechanical model of jointed rock mass requires detailed study of the modeling of the mechanical behavior of intact rock and the mechanical behavior of the intact rock along contact of interaction between them. These studies require both high qualitative and convergence of results. Therefore its necessary to use experimental results in the numerical simulation.

According to the results of performed work, we have arrived the following conclusions which are presented in next sentences. The combination of analytical and empirical methods in the numerical approach (in the finite element method) of modeling allow to take into account discontinuities and different defects of the jointed rock mass. With the created geomechanical model of jointed rock mass it is possible to obtain of stress-strain graph and the anisotropy value of the of the strength and deformation properties of jointed rock mass.

\section{References}

1. E. Hoek, M.S. Diederichs, International Journal of Rock Mechanics and Mining Sciences, 43(2), 203-215 (2006)

2. N. Barton, Journal of Rock Mechanics and Geotechnical Engineering, 5(4), 249-261 (2013)

3. L. Jing, K.B. Min, A. Baghbanan, Rock mechanics new research, 109-165 (2009)

4. E. Hoek, E.T. Brown, International Journal of Rock Mechanics and Mining Sciences, 34(8), 1165-1186 (1997)

5. Özkan, B. Erdem, A. Ceylanoğlu, International Journal of Rock Mechanics and Mining Sciences, 73, 28-41 (2015)

6. A. Palmstrom, R. Singh, Tunnelling Underground Space Technol, 16, 115-31 (2001)

7. A. Trivedi, Journal of Rock Mechanics and Geotechnical Engineering, 7, 540-565 (2015)

8. M. Sanei, L. Faramarzi, A. Fahimifar, S. Goli, A. Mehinrad, A. Rahmati, International Journal of Rock Mechanics and Mining Sciences, 75, 119-131 (2015)

9. H.W. Jing, S.Q. Yang, M.L. Zhang, G.A. Xu, K.F. Chen, Tunnelling and Underground Space Technology, 43, 184-197 (2014)

10. J.C. Jaeger, N.G.W. Cook, R.W. Zimmerman, Fundamentals of rock mechanics: 4th edition (London, 2007)

11. N. Halakatevakis, A. Sofianos, Int J Rock Mech Min Sci, 47(4), 568-582 (2010)

12. A. Khani, A. Baghbanan, S. Norouzi, H. Hashemolhosseini, International Journal of Rock Mechanics \& Mining Sciences, 60, 345-352 (2013)

13. Y. Ji. Ping, C. W. Zhong, Y. D. Sen, Y. J. Qiang, Computers and Geotechnics, 64, 20-31 (2015)

14. K.B. Min, L. Jing, Int J Rock Mech Min Sci., 40(6), 795-816 (2003)

15. X. Wang, Y. Zhao, X. Lin, Journal of Rock Mechanics and Geotechnical Engineering, 3, 398-406 (2011)

16. Y. Zhang, D. Stead, D. Elmo. Computers and Geotechnics, 65, 56-72 (2015)

17. N. Barton, Journal of Rock Mechanics and Geotechnical Engineering, 5(4), 249-261 (2013)

18. A.N. Stavrogin, B.G. Tarasov, Experimental physics and rock mechanics (results of laboratory studies) (A.A. Balkema Publishers, 2001)

19. A.N. Stavrogin, A.G. Protosenya, Mehanika deformirovaniya i razrusheniya gornih porod (Nedra, Moscow, 1992)

20. X. Yang, P.H.S.W. Kulatilake, H. Jing, S. Yang, Tunneling and Underground Space Technology, 50, 129-142 (2015)

21. T. Yang, P. Wang, T. Xu, Q. Yu, P. Zhang, W. Shi, G. Hu, Tunneling and Underground Space Technology, 48, 129-139 (2015) 
22. W. Wittke, Rock Mechanics Based on and Anisotropic Jointed Rock Model (AJRM) (Wilhelm Ernst \& Sohn, Berlin, 2014)

23. R. Usmanov, M. Rakočević, V. Murgul, N. Vatin, Applied Mechanics and Materials, 633-634, 927-931 (2014)

24. R. Usmanov, V. Murgul, N. Vatin, Applied Mechanics and Materials, 633-634, 10821085 (2014)

25. R. Usmanov, I. Mrdak, N. Vatin, V. Murgul, Applied Mechanics and Materials, 633634, 932-935 (2014)

26. I. Mrdak, M. Rakočević, L. Žugić, R. Usmanov, V. Murgul, N. Vatin, Applied Mechanics and Materials, 633-634, 1069-1076 (2014) 